\title{
Epidemiologial Survey on the Utilization of Insecticide Treated Mosquito Nets in Malaria Control among Gyadi-Gyadi Communities in Kano, Nigeria
}

\author{
Ahmad Salisu Aliyu ${ }^{1 *}$, Maimuna Yahaya Yakasai ${ }^{2}$, Nazir Lawan Habib ${ }^{1}$, Habu Chadi ${ }^{3}$ \\ ${ }^{I}$ Department Infectious Diseases Hospital (IDH), Medical Laboratory, Kano, Nigeria \\ ${ }^{2}$ Department of Chemistry, Sa'adatu Rimi College of Education, Kano State \\ ${ }^{3}$ Department of Chemistry, Bauchi State University, Gadau
}

\begin{abstract}
Background: Malaria causes an overwhelmingly large number of cases and deaths round the globe every year. Insecticide treated mosquito nets (ITNs) have raised a renewed interest to serve as tools for malaria control in Africa. This survey was, therefore, designed to provide information about the knowledge, attitude and experience of the community about malaria as a disease and its preventive methods, particularly acceptability, affordability and compliance to the use of insecticide treated mosquito nets, and factors influencing its possession and utilization of ITNs among GyadiGyadi communities in Kano, Nigeria. Methods: A community based cross-sectional study was conducted in Gyadi-Gyadi from March 2019 to April 2019. Data was collected using a pretested structured questionnaire. Descriptive analysis was performed to obtain the frequency distribution of the variables. Results: The result shows that 341 participants responded to the questionnaire. $64.5 \%$ of the respondents had heard about the mosquito net. $45 \%$ of the respondents in the survey reported the presence of at least one mosquito net in their households. $69.2 \%$ of the participants perceived fever, headache and chilling of the body as the main symptoms of malaria. Conclusion: The utilization of mosquito nets at the time of the study was very low. However, acceptability and willingness to use ITNs for malaria prevention was very high. It is recommended that communities should be strongly sensitized on the importance of ITNs for malaria control, and the availability and affordability should be insured.
\end{abstract}

Keywords: Gyadi-Gyadi, Insecticide treated mosquito nets (ITNs), Malaria, Utilization.

\section{Introduction}

Malaria is a disease caused by the protozoan parasites of the genus Plasmodium. The five species that commonly infect humans are: Plasmodium falciparum, Plasmodium vivax, Plasmodium ovale, Plasmodium malariae and Plasmodium knowlesi [1]. P. falciparum is found in the tropics and sub- tropics and it is the most important species as it is responsible for $50 \%$ of all morbidity and mortality from severe malaria. $P$. vivax is seen in tropics and sub- tropical areas and is less dangerous but more widespread. It is transmitted to humans by the bite of infected female Anopheles mosquito of more than 30 species [1]. In sub-Saharan Africa, Anopheles gambiae, Anopheles arabiensis and Anopheles funestus are the primary vectors of malaria parasites and show highly anthropophagic tendencies [1].
Malaria is a complex disease that varies widely in epidemiology and clinical manifestation in different parts of the world. This variability is caused by factors such as the species of malaria parasites that occur in a given area, their susceptibility to commonly used or available antimalarial drugs, the distribution and vectorial capacity of mosquito vectors, climate and other environmental conditions and the behaviour and level of acquired immunity of the exposed human populations. In particular, young children, pregnant women, and non-immune visitors to malaria endemic areas are at greatest risk of severe or fatal illness [2].

Early detection and prompt treatment of malaria cases, selective vector control (indoor residual spray, use of insecticide treated mosquito nets and source reduction) and 
epidemic prevention and control are the major strategies adopted in the country. So far, the application of in-house insecticide spraying has been at the center of vector control operations [3].

Malaria remains a major public health problem particularly in many tropical countries, resulting in decreased productive capacity and increased poverty despite the intensive attempts being exerted to control it especially in subSaharan Africa $[4,5,6]$.

In Nigeria, Malaria is a major public health problem where it accounts for more cases and deaths than any other country in the world. Malaria is a risk for $97 \%$ of Nigeria's population. The remaining $3 \%$ of the population live in the malaria free highlands. There are an estimated 100 million malaria cases with over 300,000 deaths per year in Nigeria. This compares with 215,000 deaths per year in Nigeria from HIV/AIDS. Malaria contributes to an estimated $11 \%$ of maternal mortality [7].

In Nigeria, malaria in pregnant women is a major public health concern because it is the major cause of maternal mortality. The major complications in pregnant women resulting from malaria are low birth weight in new-born babies, high placental plasmodia burden, foetal complications, and sometime new born death $[8,9]$.

Currently, insecticide treated mosquito nets (ITNs) have received serious attention and have raised renewed interest to serve as tools in malaria control. In Africa, the use of this control strategy has been proved to be costeffective means for the control of malaria, especially among children under 5 years of age and pregnant women $[5,6]$.

Studies conducted in different African countries have shown the effectiveness of ITNs $[10,11,12]$. Moreover, other controlled trials have also confirmed an over-all reduction in child mortality [13, 14, 15].

Thus, based on these epidemiological evidences, it could be argued that ITNs have become one of the major components of vectortargeted interventions in Africa [5, 6].

Nigeria has adopted the use of ITNs as one of its vector control strategies primarily in selected malarious areas with the view to a gradual scaling-up of the intervention. The use of mosquito nets is, however, limited and there are a number of possible explanations for this low coverage. These may be due to lack of cultural exposure to the use of mosquito nets, lack of awareness, absence of a sustainable mechanism for the distribution of ITNS, low acceptance by the community, and concerns regarding its high cost. Since this strategy, as one of the vector control options in the country, is a new initiative, understanding the perceptions and willingness of the community towards using ITNs as well as the factors influencing its usage is a prerequisite for designing strategies aimed at scaling-up mosquito net implementation programmed in Nigeria.

The rationale for selecting these areas was to initiate the introduction and implementation of ITNs in semi-urban and development project areas and gradually expand it to other malarious areas. The assumption was that the people residing in these areas might have awareness about mosquito nets and their importance in preventing malaria morbidity and mortality. These areas are mostly exempted from regular indoor residual spray activities.

Insecticide-treated nets (ITNs) have become important tools that provide a simple and effective means of preventing malaria in highly endemic areas [16]. At present large scale ITN programs are being implemented in sub-Saharan Africa, Asia and Latin America using a number of operational approaches [17].

Large-scale trials of ITNs have demonstrated that they reduce malaria mortality and morbidity under a variety of Several epidemiological conditions $[18,19$, $20,21,22,23,24,25,26]$. Results from such studies provide enough evidence to galvanize consensus in the global community that provision of ITNs should receive priority [20]. At the African summit on Roll Back Malaria in Abuja, Nigeria in April 2000, heads of states and senior representatives from 44 malaria afflicted countries in Africa agreed to a goal of providing ITNs to at least $60 \%$ of those at risk of malaria, particularly pregnant women and children less than five years of age, by 2005 [20, 27, 28, 29, 30, 31]. This target has also been set by the Ministry of Health and Roll Back Malaria partners in Kano [18]. But coverage in Africa is still unacceptably low $[31,32]$ only $3 \%$ of 
African children are sleeping under ITN, and only about $20 \%$ are sleeping under any kind of net [32].

Apart from coverage, issues regarding the utilization of ITNs are very crucial. This is because the ITNs that are available at a household level may be left unused or even if they are used, vulnerable members of the household may not be given priority and/ or the usage may be intermittent. The maximum malaria reduction impact of ITNs will only be achieved if people acquire nets, treat/ retreat them, make sure that the most vulnerable household members sleep under them, and use nets all year round [33] Discrepancies between possession and utilization have been elicited by studies carried out in different African countries [34, 35].

Yet, there is no properly documented evidence regarding the coverage and utilization of ITNs in the study locality. This survey was, therefore, designed to provide information about the knowledge, attitude and experience of the community about malaria as a disease and its preventive methods, particularly acceptability, affordability and compliance to the use of insecticide treated mosquito nets, and factors influencing its possession and utilization of ITNs among Gyadi-Gyadi communities in Kano, Nigeria.

\section{Methodology}

\section{Study Area and Study Design}

The study was conducted in Gyadi-Gyadi, which is one of the towns found in Tarauni local government Kano state. According to 2006, national housing and population census, the projected estimated population of the Gyadi-Gyadi was 65,000 . A community-based cross- sectional study was conducted using interviewer-administered questionnaire from March 2019 to April 2019.

\section{Sample Size Determination}

In this study, manual calculation of the sample size using Morgan and Krejcie [36] formula was used for sample size determination, as stated below:

$$
\mathrm{S}=\mathrm{X}^{2} \mathrm{NP}(1-\mathrm{P}) \div \mathrm{d}^{2}(\mathrm{~N}-1)+\mathrm{X}^{2} \mathrm{P}(1-\mathrm{P})
$$

Where:

$\mathrm{S}=$ Required sample size

$\mathrm{X}^{2}=$ The table value of the chi-square at desired confidence (3.841)

$\mathrm{N}=$ Study Population size (3000)

$\mathrm{P}=$ Population proportion assumed to be 0.50 since this would provide maximum sample size

$\mathrm{d}^{2}=$ Degree of accuracy of the result expressed as proportion 0.050

$3.841 \times 3000 \times 0.5 \times 0.5$

$0.0025 \times 2999+3.841 \times 0.5 \times 0.5$

$2880.75=341$

8.45775

Hence 341 participants

\section{Inclusion and Exclusion Criteria}

Resident individuals aged 18 years and above and willing to participate were included in the study. Individuals who stayed as guests in the selected households, those who were $<18$ years of age and who had chronic illnesses, were excluded from the study.

\section{Data Collection}

Data was collected from eligible and willing participants using a pre-tested, structured questionnaire, adapted from the sample questionnaire in the guide to developing knowledge, attitude and practice surveys developed by the World Health Organization and Stop malaria Partnership. Socio-demographic information including age, gender, occupation, education, and socio-economic status were collected. The knowledge of the participants on symptoms suggestive of malaria, cause of malaria, treatment and preventive measures, attitude and practices regarding malaria disease were also collected.

\section{Data Analysis}

Data were analyzed using Statistical Package for Social Science (SPSS) software version 16.0 at that time with the help of the Statistician. The descriptive statistical method was used to analyze frequencies and percentages.

\section{Ethical Considerations}

This study was conducted only after obtaining approval from Gyadi-Gyadi District Head. 


\section{Results}

A total of 341 respondents were interviewed, giving 100\% response rate. The majority, 201 (58.9\%) of the respondents were males. Among all, $91(26.7 \%)$ of respondents were $31-35$ years of age. Of the study subjects, $223(65.4 \%)$, were married. The socio-economic characteristics of the study showed that, among all respondents, $221(64.8 \%)$ of respondents attended formal education, among this 145 $(42.5 \%)$ of respondents were primary school completed, $76(22.3 \%)$ of respondents were secondary school and above completed, while $120(35.2 \%)$ of respondents reported that they were took informal education (were illiterate and only read and write). Similarly, results of occupational status of respondents indicated, $150(44 \%)$ of respondents were farmers, 46 (13.5\%) were Government employed, 70 (20.5\%) were Merchants and $75(22 \%)$ were House wives (Table 1).

Table 1. Socio Demographic Characteristics of the Participants $(n=341)$

\begin{tabular}{|l|l|l|}
\hline Characteristics & Frequencies (n=341) & $\begin{array}{l}\text { Percentages } \\
\%\end{array}$ \\
\hline Gender & 201 & 58.9 \\
\hline Males & 140 & 41.1 \\
\hline Females & \multicolumn{2}{|l|}{} \\
\hline Ages & 60 & 17.6 \\
\hline $20-25$ & 70 & 20.5 \\
\hline $26-30$ & 91 & 26.7 \\
\hline $31-35$ & 72 & 21.1 \\
\hline $36-40$ & 48 & 14.1 \\
\hline $41+$ & \multicolumn{2}{|l|}{} \\
\hline Marital Status & 223 & 65.4 \\
\hline Married & 96 & 28.2 \\
\hline Single & 9 & 2.6 \\
\hline Divorce & 13 & 3.8 \\
\hline Widowed & 75 & 22 \\
\hline Education & 45 & 13.2 \\
\hline Illiterate & 145 & 42.5 \\
\hline Can read and write & 76 & 22.3 \\
\hline Primary & 22 \\
\hline Secondary and above & 75 & 44 \\
\hline Occupation & 150 & 13.5 \\
\hline House wife & 46 & 20.5 \\
\hline Farmers & 70 & \\
\hline Government employee & \\
\hline Merchants & \multicolumn{2}{|l|}{} \\
\hline
\end{tabular}

Majority of the households Ever heard about the mosquito net 220 (64.5\%), majority of the households did not own any mosquito net, the main reasons cited being inability to afford the price 95 (27.9\%), Shortage of nets during free provision 49 (14.4\%) Not knowing its use 47 (13.8\%) Surprisingly, 228 (45\%) of the respondents Possess at least one mosquito net.
However, $200(30 \%)$ of the respondents Possess at least one ITNs. With regard to the sources of ITNs, majority of the respondents $164(48.1 \%)$ said they obtained the ITNs from health institution, freely. Similarly, 224 $(65.7 \%)$ of the respondents said that the Duration of the possession of the nets are 1-5 years (Table 2). 
Table 2. Mosquito Net Possession among the Studied Households $(n=341)$

\begin{tabular}{|c|c|c|}
\hline Characteristics & Frequencies $(\mathrm{n}=341)$ & Percentages $(\%)$ \\
\hline \multicolumn{3}{|l|}{ Ever heard about the mosquito net } \\
\hline Yes & 220 & 64.5 \\
\hline No & 121 & 35.5 \\
\hline \multicolumn{3}{|l|}{ Possession of at least one mosquito net } \\
\hline Yes & 228 & 45 \\
\hline No & 113 & 55 \\
\hline \multicolumn{3}{|l|}{ Possession of at least one ITN } \\
\hline Yes & 200 & 30 \\
\hline No & 141 & 50 \\
\hline Possession of at least 2 mosquito nets & & 20 \\
\hline 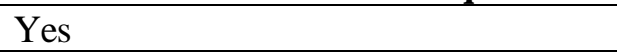 & 140 & \\
\hline No & 201 & 8 \\
\hline Possession of at least 2 ITNs & & 65.3 \\
\hline Yes & 131 & 21.7 \\
\hline No & 210 & 5 \\
\hline \multicolumn{3}{|c|}{ Number of any mosquito net possessed } \\
\hline One & 158 & 7 \\
\hline Two or more & 183 & 93 \\
\hline \multicolumn{3}{|l|}{ Number of ITNs possessed } \\
\hline One & 174 & 51.0 \\
\hline Two or more & 167 & 49.0 \\
\hline \multicolumn{3}{|c|}{ Cumulative number of nets identified during the study } \\
\hline Any mosquito net & 245 & 71.8 \\
\hline ITNs & 96 & 28.2 \\
\hline \multicolumn{3}{|c|}{ Nets observed and presence confirmed } \\
\hline Yes & 318 & 93.3 \\
\hline No & 23 & 6.7 \\
\hline \multicolumn{3}{|l|}{ Source of nets } \\
\hline From health institution, freely & 164 & 48.1 \\
\hline From health institution, with payment & 25 & 7.3 \\
\hline Bought from market/ shop & 112 & 32.8 \\
\hline From other source, freely & 21 & 6.2 \\
\hline From other source, with payment & 19 & 5.6 \\
\hline \multicolumn{3}{|l|}{ Duration of possession of the nets } \\
\hline$<1$ year & 106 & 31.1 \\
\hline $1-5$ years & 224 & 65.7 \\
\hline$\geq 6$ years & 9 & 2.6 \\
\hline Don't remember & 2 & 0.6 \\
\hline \multicolumn{3}{|l|}{ Brand of nets } \\
\hline PermaNet & 221 & 64.8 \\
\hline UNICEF & 102 & 29.9 \\
\hline SafeNite & 12 & 3.5 \\
\hline PowerNet & 3 & 0.9 \\
\hline Olyset & 1 & 0.3 \\
\hline Net Mark & 1 & 0.3 \\
\hline Unknown & 1 & 0.3 \\
\hline \multicolumn{3}{|c|}{ Reason for not owning any mosquito nets } \\
\hline inability to afford the price & 95 & 27.9 \\
\hline
\end{tabular}




\begin{tabular}{|l|l|l|}
\hline Shortage of nets during free provision & 49 & 14.4 \\
\hline Not knowing its use & 47 & 13.8 \\
\hline Absence of mosquitoes & 38 & 11.1 \\
\hline Using other preventive methods & 39 & 11.4 \\
\hline Not knowing where to find it & 36 & 10.6 \\
\hline Other reason & 37 & 10.8 \\
\hline Desire to possess mosquito nets in the future \\
\hline Yes & 199 & 58.3 \\
\hline No & 81 & 23.8 \\
\hline Can't tell & 61 & 17.9 \\
\hline Preferred way of obtaining nets & 187 & 54.8 \\
\hline If distributed freely & 154 & 45.2 \\
\hline If sold with discount
\end{tabular}

Majority of the respondents $282(82.7 \%)$ used available nets, and the frequency of using the nets was consistent throughout the year 218 (63.9\%). Similarly, $265(77.7 \%)$ of the respondents sleep under the ITNs. However, majority of the households did not use any

mosquito net, the main reasons cited being Absence of mosquitoes 61 (17.9\%), old and worn-out net $57(16.7 \%)$, It is hot sleeping under a net $46(13.5 \%)$, Children may get trapped in it 45 (13.2\%), Difficult to get up at night 44 (12.9) (Table 3).

Table 3. Mosquito Net Utilization Pattern $(n=341)$

\begin{tabular}{|c|c|c|}
\hline Characteristics & Frequencies $(n=341)$ & Percentages $(\%)$ \\
\hline \multicolumn{3}{|l|}{ Using the available nets } \\
\hline Yes & 282 & 82.7 \\
\hline No & 59 & 17.3 \\
\hline \multicolumn{3}{|l|}{ Frequency of using the nets } \\
\hline Consistently throughout the year & 218 & 63.9 \\
\hline Intermittently & 123 & 36.1 \\
\hline \multicolumn{3}{|l|}{ Times when intermittent users use their nets } \\
\hline During rainy season & 96 & 28.2 \\
\hline After rainy season & 75 & 22 \\
\hline During dry season & 57 & 16.7 \\
\hline As they like & 57 & 16.7 \\
\hline When hearing mosquitoes buzzing & 56 & 16.4 \\
\hline \multicolumn{3}{|l|}{ Use of any net the preceding night } \\
\hline Yes & 242 & 71.0 \\
\hline No & 99 & 29.0 \\
\hline \multicolumn{3}{|l|}{ Did anyone sleep under an ITN last night } \\
\hline Yes & 265 & 77.7 \\
\hline No & 76 & 22.3 \\
\hline \multicolumn{3}{|l|}{ Reason why nets are not being used } \\
\hline Absence of mosquitoes & 61 & 17.9 \\
\hline old and worn-out net & 57 & 16.7 \\
\hline It is hot sleeping under a net & 46 & 13.5 \\
\hline Children may get trapped in it & 45 & 13.2 \\
\hline Lack of appropriate place for hanging the net & 44 & 12.9 \\
\hline It takes time to tuck in the net each night & 44 & 12.9 \\
\hline Difficult to get up at night & 44 & 12.9 \\
\hline $\begin{array}{l}\text { The fact that malaria can be transmitted from } \\
\text { patient to another person through mosquito } \\
\text { es was known to } 55.7 \% \text { of the respondents. } \\
\text { her modes of transmission mentioned by the }\end{array}$ & \multicolumn{2}{|c|}{$\begin{array}{l}\text { participants were Contact with a malaria patien } \\
19(5.6 \%) \text {. Stagnant water } 189(55.4 \%) \text { was the } \\
\text { most commonly mentioned breeding site of } \\
\text { mosquito and the other site reported were Dirty }\end{array}$} \\
\hline
\end{tabular}


areas $120(35.2 \%)$. Nearly Mosquito net and one or more of the above measures $68(19.9 \%)$ of the participants knew that malaria transmission is preventable and 50 (14.7\%) mentioned that cleaning the surroundings could prevent malaria transmission (Table 4).

Table 4. Knowledge on Malaria Transmission, Mosquito Breeding Sites and Prevention Methods $(n=341)$

\begin{tabular}{|l|l|l|}
\hline Characteristics & Frequencies (n=341) & Percentages (\%) \\
\hline Mode of malaria transmission & 190 & 55.7 \\
\hline Mosquito bite & 19 & 5.6 \\
\hline Breathing bad air & 19 & 5.6 \\
\hline Contact with a malaria patient & 18 & 5.3 \\
\hline Exposure to rain & 18 & 5.3 \\
\hline Bad smell & 13 & 3.8 \\
\hline Eating maize stalk & 16 & 4.7 \\
\hline Wind/cold air & 4 & 1.2 \\
\hline Bedbug/flea & 44 & 12.9 \\
\hline Others & \multicolumn{2}{|l|}{} \\
\hline Mosquito breeding sites & 189 & 55.4 \\
\hline Stagnant water & 120 & 35.2 \\
\hline Dirty areas & 11 & 3.2 \\
\hline Didn't know & 21 & 6.2 \\
\hline Others & \multicolumn{2}{|l|}{} \\
\hline Prevention methods & 50 & 14.7 \\
\hline Cleaning the surroundings & 20 & 16.1 \\
\hline Draining and filling ditches & 55 & 19.1 \\
\hline Insecticides spraying & 65 & 7.0 \\
\hline Chemotherapy & 24 & 7.0 \\
\hline Fumigation and fire smoking & 24 & 10.3 \\
\hline Mosquito net & 35 & 19.9 \\
\hline $\begin{array}{l}\text { Insecticides and one or more of } \\
\text { the above measures }\end{array}$ & $\begin{array}{l}\text { Mosquito net and one or more of } \\
\text { the above measures }\end{array}$ & 68 \\
\hline
\end{tabular}

On the other hand, $69.2 \%$ of the study participants perceived fever, headache and chills as the main signs and symptoms of malaria. More than $48.9 \%$ of the interviewees, also correctly identified the names of the currently used anti-malarial drugs, name Chloroquine and Artemether. With regard to malaria, morbidity and preference of health facilities, $58.4 \%$ of the respondents had their first visit to health care facilities including public and private health services as well as malaria control laboratories, drug venders/pharmacy and Community Health Workers (CHWs) seeking treatment for malaria. A few of the respondents also reported the use of herbalists and other health care providers. About $46.6 \%$ of the households had two to five family members who were sick due to malaria and $38.7 \%$ had only one family member who was sick of the disease (Table 5).

Table 5. Knowledge about the Symptoms of Malaria, Antimalarial Drugs and Preference of Health Service Visit for Malaria Illness $(n=341)$

\begin{tabular}{|c|c|c|}
\hline Characteristics & Frequencies $(n=341)$ & Percentages $(\%)$ \\
\hline \multicolumn{3}{|c|}{ Signs and symptoms of malaria } \\
\hline Fever, headache, chills & 236 & 69.2 \\
\hline Joint and muscle pain, & 34 & 10.0 \\
\hline Nausea and vomit & 71 & 20.8 \\
\hline \multicolumn{3}{|l|}{ Antimalarial drugs } \\
\hline Chloroquine & 167 & 48.9 \\
\hline
\end{tabular}




\begin{tabular}{|l|l|l|}
\hline Artemether & 63 & 18.5 \\
\hline Chloroquine and Artemether & 91 & 26.7 \\
\hline Other & 20 & 5.9 \\
\hline First visit when sick of malaria & \multicolumn{2}{|l|}{} \\
\hline Government health care facility & 199 & 58.4 \\
\hline Malaria control laboratory & 49 & 14.4 \\
\hline Private clinics & 18 & 5.3 \\
\hline Drug vendor/pharmacy & 40 & 11.7 \\
\hline Community health workers & 22 & 6.4 \\
\hline Herbalist & 13 & 3.8 \\
\hline Number of family members sick of malaria in 2 weeks \\
\hline None & 50 & 14.7 \\
\hline 1 & 132 & 38.7 \\
\hline $2-5$ & 159 & 46.6 \\
\hline
\end{tabular}

\section{Discussion}

The aim of this study was to assess the knowledge, perceptions, and practices of the community about malaria, as well as its transmission and prevention methods. Furthermore, it aimed to determine the coverage of ITNs mainly in urban and semiurban areas, and factors influencing its possession and usage.

The awareness about the association between mosquito and malaria in the present study is much higher than the findings reported in previous studies $[37,38]$. The study participants included in this study were mainly from the urban areas unlike those of the previous studies who resided mainly in rural areas. In addition, different interventions, particularly those made to raise the awareness of the community about malaria and its control in the urban areas could be a possible explanation for the high awareness of malaria. In this study, the respondents indicated that stagnant water is the main mosquito breeding site. Previous studies have also confirmed similar findings [37, 39, 40]. The awareness of the relationship between mosquitoes and malaria transmission in the study community is highly important for the possession and utilization of mosquito nets. It is speculated that knowledge of this association predicts high mosquito net use.

Almost all the participants in this study had knowledge about the main signs and symptoms suggestive of malaria, as in all studies. Knowledge is usually high in areas with low-tomoderate transmission rates and where people are aware of the clinical manifestations of the disease [37, 38, 39, 40]. However, it might be low in areas of holo-endemic transmission where the population has protective immunity against malaria [39].

The medications taken for the treatment of malaria episode were mainly antimalarial drugs. Unlike in the rural areas, malaria cases in our study area were usually first identified and treated in public health care facilities and malaria control laboratories. The utilization of private health facilities, traditional herbal remedies, and community health workers was very low in the study areas. This is mainly due to the fact that the coverage and accessibility of public health facilities in the study area is relatively high compared to that in rural malarious areas. However, it has been demonstrated that the coverage of malaria control can be increased substantially by involving communities particularly by training community health workers and mother coordinators, especially on correct antimalarial drug use for children [41, 42].

This study highlights several important issues for the implementation of ITNs as a malaria control strategy. The proportion of people who had not heard about ITNs was significant $(35.5 \%)$. Similarly, the proportion of households who owned ITNs among those who had heard about it was only $28.2 \%$. Among these, those who reported inappropriate use of ITNs were nearly $17.3 \%$. A gap exists between those who have heard about ITNs and those who owned it, and between those who possessed and used mosquito nets appropriately. This discrepancy could be because of either the awareness of the community about ITNs is poor or may reflect the relative unavailability of mosquito nets, suggesting that, at the time of the survey; mosquito net use for malaria control was not 
being adequately promoted in many parts of the country.

This study also suggests ways of increasing demand in relation to the implementation of ITN programme. For example, a significant proportion $(35.5 \%)$ of households who are willing to buy would prefer making payments in installments. This may ensure greater coverage and make ITN affordable to those who may not be able to purchase it immediately and in cash.

The other important issue that should not be overlooked with regard to the affordability of ITNs is the time when the households would need ITN and the time when they would have most money available to buy them. Because of seasonality of crops and income generated, people residing in most parts of the country may prefer to purchase ITN after the harvest. If the perceived risk of malaria is low during these times, spending money on ITNs may not be perceived as a high priority [43]. But when the need is perceived as highest, people may not have adequate money for buying mosquito nets. The time for the occurrence of peak malaria transmission associated with epidemics in Nigeria is during the months of July to October.

The affordability and possession of mosquito nets are not the only factors that affect ITN use and acceptance. The seasonality of malaria and mosquito abundance is also equally important. In surveys conducted in Ghana, net use was considerably higher in the rainy season than the dry season, mainly due to the abundance of mosquitoes as nuisances and the perceived risk of malaria during the rainy season [43]. This is particularly true for Nigeria, where the transmission of malaria and abundance of mosquito population vary across the seasons of the year. When the perceived malaria risk and mosquito density is high, mosquito nets are highly used. But when the mosquito density coupled with malaria risk is low, people may not see the need for continued mosquito net use.

Therefore, the seasonality of malaria and unavailability of mosquito nets for the needy people with an appropriate price can be the barriers against the high coverage of mosquito net particularly in poor rural communities.
These community factors have to be taken into considerations during the implementation of ITN programmes.

\section{Limitation}

This study was not conducted without a limitation. The study was carried out mainly in urban and peri-urban areas during March and April 2019 the time when malaria problem in the country is low. This could lead the respondents to underestimate the risk for malaria and willingness to purchase mosquito nets. It could have been better to undertake such kind of studies during the peak transmission of malaria both in urban and rural areas to elucidate the heartfelt needs of the community. Nevertheless, this study provides useful information about malaria and ITNs that may be of practical importance.

\section{Conclusion}

In conclusion, the utilization of mosquito nets at the time of this survey was very low. However, acceptability and willingness of the community to use ITNs for malaria prevention was very high. It is expected that the expansion of ITN implementation and increasing its coverage both in the urban and rural malarious areas of the country may lead to the success of malaria control. To this end, it is recommended that communities should be strongly sensitized on the importance of treated mosquito nets for malaria prevention and the availability and affordability should be insured. As regular assessment and monitoring of net possession and use provide the best available means to track progress in coverage with this principal malaria intervention, district level rapid assessments of household possession and usage of nets should be encouraged and supported for program evaluation.

\section{Conflicts of Interest}

The authors declare that they have no conflicts of interest.

\section{Acknowledgments}

I am grateful to thank the study participants and acknowledge the team of research assistants. 


\section{References}

[1] World Health Organization. World malaria report. Geneva, Switzerland. (2011); 32-42.

[2] Bloland Peter B. Drug resistance in malaria. WHO/CDS/CSR/DRS. (2001); 4:1-32.

[3] Ministry of Health. National Five-Year Strategic Plan for Malaria Control in Ethiopia: (2001- 2005). Malaria and Other Vector Borne Diseases Prevention and Control Team, Disease Prevention and Control Department, Ministry of Health, Addis Ababa, (2001).

[4] World Health Organization. A global strategy for malaria control. Geneva, Switzerland, (1993).

[5] World Health Organization. WHO expert committee on malaria: twentieth report. Technical Report Series (No. 892), (2000).

[6] World Health Organization. The Abuja declaration and plan of action: an extract from the African summit on the Roll Back Malaria. WHO/CDS/RBM/2000.17.Geneva. Switzerland, (2000)

[7] Federal Ministry of Health. A road map for malaria control in Nigeria, a bridged version, Abuja. Strategic Plan. (2009-2013); Yahian Press Ltd. 2010; 155

[8] Erhabor O., Adias T.C and M.L. Hart (2010). Effect of falciparum malaria on the indices of anaemia among pregnant women in the Niger Delta of Nigeria. Journal of Clinical Medicine and Research, 2(3):035-041.

[9] Jenavine O. Mbah, Njoku O. O, Agwu U. Nnachi, Ijem A. Nnachi, Amacchi J. Nwinyimagu (2015) Incidence of antenatal malaria parasi-taemia and the effects on the haemoglobin pro-file of the pregnant women in Enugu East Local Government Area, Enugu, Nigeria. American Journal of Epidemiology and Infectious Dis-ease, 3(5): 88-94. [10] Choi, H.W., Breman, J.G., Teutsch, S.M., Liu S, Hightower, A.W. and Sexton, J.D. The effectiveness of insecticide-impregnated bed nets in reducing cases of malaria infection: a meta-analysis of published results. Am J Trop Med Hyg (1995); 52(5): 377-382

[11]Binka F.N., Kubaje, A., Adjuik, M., Williams, M.K, Lengeler, C., Maude, G.H. et al. Impact of permethrin impregnated bed nets on child mortality in Kassena- Nankana district, Ghana: a randomized controlled trial. Trop Med Int Health (1996); 1:147154.

[12]Nevill, C.G, Some, E.S., Mung'ala V.O., Muteme, W., New, L., Marsh K. et al. Insecticidetreated bednets reduce mortality and severe morbidity among children on the Kenyan coast.
Trop Med Int Health (1996), 1:139-146.

[13] Alonso, P.L., Lindsay, S.W., Armstrong, S.J., Konteh, M., Hill, A.G., David, P.H. et al. The effect of insecticide-treated bed nets on mortality of Gambian children. Lancet (1991); 337: 1499-1502.

[14] Alonso, P.L., Lindsay, S.W., Armstrong, S.J., Konteh, M., Keita K., Marshal, C. et al. A malaria control trial using insecticide-treated bed nets and targeted Chemoprophylaxis in a rural area of The Gambia, West Africa 5: design and implementation of the trial. Trans R Soc Trop Med Hyg (1993); $87: 31-36$.

[15]D'Alenssadro, U., Olaleye, B.O., McGuire, W., Langerock, P., Bennet, S., Aikins, M.K. et al. Mortality and morbidity for malaria in Gambian children after introduction of an impregnated bed net program. Lancet (1995); 345: 479-483.

[16] Greenwood BM, Bojang K, Whitty CJ, Targett GA. Malaria. Lancet (2005);365(9469):1487-98.

[17]Lengeler C. Insecticide-treated nets for malaria control: real gains. Bulletin of the World Health Organization. (2004); 82:84.

[18]Ministry of Health/UNICEF in Ethiopia. GUIDE for program managers on the use of insecticide-treated nets in Ethiopia. July (2002).

[19] Okrah J, Traore C, Pale A, Sommerfeld J and Müller O. Community factors associated with malaria prevention by mosquito nets: an exploratory study in rural Burkina Faso. Tropical Medicine and International Health (2002); 7 (Issue 3): 240.

[20]Nahlen BL, Clark JP, and Alnwick D. Insecticide- treated Bed Nets. Am J Trop Med Hyg (2003);68(suppl 4):1-2.

[21]Abdulla S, Gemperli A, Mukasa O, et al. Spatial effects of the social marketing of insecticide-treated nets on malaria morbidity. Trop. Med Int. Health (2005); 10(1):11-8.

[22]Adongo PB, Kirkwood B, Kendall C. How local community knowledge about malaria affects insecticide-treated net use in northern Ghana. Trop. Med. Int. Health (2005); 10(4):366-78.

[23]Rowland M, Webster J, Saleh P, et al. Prevention of malaria in Afghanistan through social marketing of insecticide-treated nets: Evaluation of coverage and effectiveness by cross-sectional surveys and passive surveillance. Tropical Medicine and International Health (2002); 7(issue 10):813.

[24] Phillips-Howard PA, Nahlen BL, Alaii JA, et al. The efficacy of permethrin treated bed nets on child mortality and morbidity in western Kenya I. 
Development of infrastructure and description of study site. Am. J. Trop. Med. Hyg. (2003);68(4 suppl):3-9.

[25]Ter Kuile FO, Terloun DJ, Kariuki SK, et al. Impact of Permethrin Treated Bed Nets on Malaria, Anemia and Growth in Infants in an Area of Intense Perennial Malaria Transmission in Western Kenya. Am. J. Trop. Med. Hyg. (2003): 68(4 suppl): 68-77.

[26]Gamble C, Ekwaru JP, Ter Kuile FO. Insecticide- treated nets for preventing malaria inpregnancy. Cochrane Database of Syst Rev. (2006) Apr 19; (2): CD003755.

[27]Negash K, Jima D, Nafo-Traore F, et al. Ethiopian Roll Back Malaria Consultative Mission: Essential Actions to Support the Attainment of the Abuja Targets. $16^{\text {th }}$ to $20^{\text {th }}$ February (2004).

[28] Anyanwu EC, Ehiri JE, Kanu I, Morad M, Ventegodt S, Merrick J. Assessing the effects of long-term exposure to insecticide treated mosquito nets in the control of malaria in endemic regions. Scientific world Journal (2004); 4:97888.

[29]Roll Back Malaria. (2001-2010) United Nations Decade to Roll Back Malaria: Insecticidetreated Mosquito Nets. RBM info sheet. Accessed through: http://www.rbm.who.int. (Accessed on: 15/ 08/ 2006).

[30]Abuja Declaration and the Plan of Action: An Extract from the African Summit on Roll Back Malaria, Abuja, 25 April (2000) (WHO/CDS/RBM/ 2000.17). Available at: http://www.rbm.who.int/docs/abuja_declaration_f inal.htm. (Accessed on: 15/ 08/ 2006).

[31] Worrall E, Hill J, Webster J, and Mortimer J. Experience of targeting subsidies on insecticidetreated nets: What do we know and what are the knowledge gaps? Trop. Med. Int. Health (2005); 10(1): 19-31.

[32]Hill J, Lines J, Rowland M. Insecticidetreated nets. Adv Parasitol. (2006); 61:77-128.

[33]Net Mark research (1999-2006). Available at: http://www.netmarkafrica.org/research. (Accessed on: 15/ 08/2006).
[34]Macintyre K, Keating J, Okbaldt YB, et al. Rolling out insecticide treated nets in Eritrea: examining the determinants of possession and use in malarious zones during rainy seasons. Trop Med Int Health. (2006) Jun; 11(6): 824-33.

[35] Tsuyuoko R, Midizi SM, Dziva P, Makunike B. The acceptability of insecticide treated mosquito nets among community members in Zimbabwe. Cent Afr J Med. (2002) Jul-Aug; 48 (7-8):87-91.

[36]Morgan DW and Krejcie, RV. (1970). Determining Sample size for research activities of Minnesota: USA.

[37]Deressa, W., Ali, A., Enquosellassie F. Knowledge, attitude and practice about malaria, the mosquito and antimalarial drugs in a rural community. Ethiop J Health Dev (2003); 17(2): 99104.

[38] Yeneneh, H., Gyorkos, T.W., Joseph, L., Pickering, J. and Tedla, S. Antimalarial drug utilization by women in Ethiopia: a knowledgeattitudes-practice study. Bull World Health Org (1993); 71: 763-772.

[39] Ongore, D., Kamunvi, F., Knight, R., and Minawa, A. A study of knowledge, attitudes and practices (KAP) of a rural community on malaria and the mosquito vector. East Afr Med J (1989); 66(2): 79-89.

[40] Klein, R.E., Weller, S.C., Zeissig, R., Richards, F.O. and Ruebush, T.K. Knowledge, beliefs, and practices in relation to malaria transmission and vector control in Guatemala. Am J Trop Med Hyg (1995); 52(5): 383-388.

[41] Gebreyesus, T.A., Witten, K.H., Getachew, A. et al. The community-based malaria control in Tigray, northern Ethiopia. A review of programme set-up, activities, outcomes and impact. Parasitologia (2000); 42: 255-240.

[42] Kidane, G. and Morrow, R.H. Teaching mothers to provide home treatment of malaria in Tigray, Ethiopia: a randomized trial. Lancet (2000); 356(9229): 550-555.

[43]Binka, F.N. and Adonso. P. Acceptability and use of insecticide impregnated bed nets in northern Ghana. Trop Med Int Health (1997); 2(5): 499-507. 